\title{
Impact of Maternal Physical Activity and Infant Feeding Practices on Infant Weight Gain and Adiposity
}

\author{
Lisa Chu, ${ }^{1}$ Ravi Retnakaran, ${ }^{2,3}$ Bernard Zinman, ${ }^{2,4}$ Anthony J. G. Hanley, ${ }^{2,3,5}$ \\ and Jill K. Hamilton ${ }^{1,3}$ \\ ${ }^{1}$ The Hospital for Sick Children, Department of Pediatrics, University of Toronto, 555 University Avenue, Toronto, ON, \\ Canada M5G 1 X8 \\ ${ }^{2}$ Leadership Sinai Centre for Diabetes, Mount Sinai Hospital, Joseph and Wolf Lebovic Health Complex, 60 Murray Street, \\ Toronto, ON, Canada M5T 3L9 \\ ${ }^{3}$ Division of Endocrinology, University of Toronto, Toronto, ON, Canada \\ ${ }^{4}$ Samuel Lunenfeld Research Institute, Mount Sinai Hospital, Joseph and Wolf Lebovic Health Complex, \\ 600 University Avenue, Toronto, ON, Canada M5G 1 X5 \\ ${ }^{5}$ Department of Nutritional Sciences, University of Toronto, FitzGerald Building, 150 College Street, Toronto, ON, Canada M5S $3 E 2$
}

Correspondence should be addressed to Jill K. Hamilton, jill.hamilton@sickkids.ca

Received 9 March 2012; Revised 25 June 2012; Accepted 11 July 2012

Academic Editor: Jack R. Wall

Copyright $\odot 2012$ Lisa Chu et al. This is an open access article distributed under the Creative Commons Attribution License, which permits unrestricted use, distribution, and reproduction in any medium, provided the original work is properly cited.

Increasing evidence supports the contribution of intrauterine environmental exposures on obesity risk in offspring. Few studies have included maternal and infant lifestyle factors. Our objective was to study the impact of maternal physical activity, infant feeding, and screen time on offspring weight gain and adiposity. In a prospective cohort study, 246 mothers underwent testing during pregnancy to assess glucose tolerance status and insulin sensitivity. Anthropometry and questionnaires on physical activity, infant feeding, and screen time were completed. Multiple-linear regression was performed to examine the impact of maternal and infant factors on infant weight gain and weight-for-length $z$-score at 1 year. Infant weight outcomes were negatively predicted by maternal pregravid vigorous/sport index and exclusive breastfeeding duration. After adjustment, each unit increase in maternal pregravid vigorous/sport index decreased infant weight gain by $218.6 \mathrm{~g}(t=2.44, P=0.016)$ and weight-for-length $z$-score by $0.20(t=2.17, P=0.031)$. Each month of exclusive breastfeeding reduced infant weight gain by $116.4 \mathrm{~g}(t=3.97, P<0.001)$ and weight-for-length $z$-score by $0.08(t=2.59, P=0.01)$. Maternal pregravid physical activity and exclusive breastfeeding duration are associated with weight gain and adiposity as early as 1 year of age.

\section{Introduction}

The increasing prevalence of childhood obesity, especially in preschool aged children $[1,2]$, has stimulated research targeting critical periods of growth. According to Freinkel's hypothesis of "fuel-mediated teratogenesis," the intrauterine environment can influence changes in gene expression and affect the development and maturation of fetal organs and tissues $[3,4]$. The postnatal period up to 2 years of age is also a critical period of growth [5]. Indeed, rapid infant weight gain is associated with an increased risk of obesity and metabolic consequences later in life [5-8].
Emerging evidence suggests that several key factors may influence infant weight gain and adiposity. These include metabolic parameters such as in utero glucose exposure [911], maternal prepregnancy body mass index (BMI) [12-14], and maternal insulin sensitivity during pregnancy [15]. In a cohort of low-income children, maternal obesity during pregnancy more than doubled the risk of obesity in children [13]. Maternal diet and physical activity during pregnancy [16-19], as well as smoking may impact offspring risk of obesity and metabolic risk [20-23]. However, there is a paucity of literature examining these risk factors in very young children. 
Infant feeding practices may also modulate later obesity risk. In particular, breastfeeding has a protective role against the development of obesity [24-27]. Harder et al. reported a dose-dependent association between breastfeeding and risk of obesity, where each month of prolonged breastfeeding decreased obesity risk in the child [28]. Beyond the first few months of life, breast-fed infants gained less weight than formula-fed infants [29]. Another study showed weight gain from 6 to 12 months was less in infants exclusively breastfed for $\geq 5$ months compared to $\leq 2$ months [30]. Earlier introduction to complementary foods may also contribute to increased risk of childhood overweight $[14,31]$, however the evidence is inconsistent [32]. Additionally, reduced physical activity and increased screen time (television and video) are associated with obesity risk in older children, although limited data is available in infants $[33,34]$.

There is little known about the impact of maternal and infant lifestyle on weight gain and adiposity at 1 year of life. The effect of screen time in infants on weight gain and adiposity has not been included as a potential factor in prior statistical models. There is also little information on the effect of maternal physical activity on weight outcomes of offspring. The objective of our study was to determine how maternal physical activity, maternal insulin sensitivity $\left(\mathrm{IS}_{\mathrm{OGTT}}\right)$, prepregnancy $\mathrm{BMI}$, infant feeding practices (breastfeeding duration, age of introduction of formula, and complementary foods), and screen time contribute to infant weight gain and adiposity at 1 year of age.

\section{Methods}

The study protocol was approved by the Research Ethics Board at Mount Sinai Hospital and the Hospital for Sick Children. Study participants consisted of pregnant women attending outpatient obstetrics clinics in Toronto, Ontario. Participants were recruited for this prospective cohort study at the time of antepartum gestational diabetes mellitus (GDM) screening and were consented to be followed into the postpartum. All consenting women then completed a 3$\mathrm{h}$ oral glucose tolerance test (OGTT) in late 2 nd or early 3rd trimester. The OGTT was performed in the morning following an overnight fast. Venous blood samples were drawn at baseline, 60,120, and 180 min after ingestion of a standard $100 \mathrm{~g}$ glucose load. The pregnant women were then classified into 3 glucose tolerance groups: (1) GDM, as defined by the National Diabetes Data Group (NDDG) criteria (requires at least two of the following: fasting glucose $\geq 5.8 \mathrm{mmol} / \mathrm{L}, 1 \mathrm{~h}$ postload glucose $\geq 10.6 \mathrm{mmol} / \mathrm{L}$, $2 \mathrm{~h}$ postload glucose $\geq 9.2 \mathrm{mmol} / \mathrm{L}$, or $3 \mathrm{~h}$ postload glucose $\geq 8.1 \mathrm{mmol} / \mathrm{L}$ ); (2) gestational impaired glucose tolerance (GIGT), defined as meeting only one of the above criteria; (3) normal glucose tolerance (NGT), defined as not meeting any of the NDDG criteria [35].

Mothers and infants were asked to attend a followup visit at 1-year postpartum. Parental demographics, medical history and anthropometrics were collected during pregnancy at the time of the OGTT. Data collected included maternal age, maternal prepregnancy weight, maternal and paternal ethnicity, family history of diabetes, socioeconomic status, and maternal physical activity indices. Maternal IS OGTT $_{\text {OG }}$ was calculated from the OGTT using the Matsuda index, which is well correlated with insulin sensitivity derived from the euglycemic-hyperglycemic clamp method [36]. Physical activity was assessed using the Baecke questionnaire, which has been validated in several populations including women of child-bearing age $[37,38]$. The questionnaire was completed during the OGTT, with participants reporting on their physical activity in the year preceding the pregnancy. The Baecke questionnaire measures three domains of physical activity: (i) occupation-associated activity (work index); (ii) sport-related physical activity (vigorous/sport index); (iii) leisure-time physical activity not including sports (leisure index). The work index quantifies the exertion related to occupational activities, including sitting, standing, lifting, and walking, as well as effects on the individual (e.g., fatigue and perspiration). The sport index characterizes vigorous/sport activity with respect to intensity (using the updated compendium of physical activities) [39]. These indices were calculated on a scale from $1-5$, where 5 represented the highest level of physical activity for each category. For example, a score of 3 out of 5 for leisure index might indicate "sometimes" walking or cycling for 15-30 min and "seldom" watching television. Mean parental education score and occupation score was calculated on a scale of 17 and 1-9, based on the Hollingshead index, an established surrogate index of socioeconomic status [40]. A maximum averaged parental score of 62 indicated the highest level of education and profession.

Infant information collected at birth included length of gestation, gender (male or female), and birth weight. At the 1 year visit, infant weight and length were measured, and weight-for-length $z$-score was calculated according to the World Health Organization (WHO) 2006 child growth standards [41] to provide a surrogate measure of adiposity. The infant lifestyle questionnaire was completed by the mothers when the infants were 3 and 12 months of age and provided information on exclusive breastfeeding duration, age of introduction to formula and cereal, and screen time based on predictors found to be important for the development of obesity (average daily exposure to TV or video viewing, meals eaten while TV is on, TV in bedroom) $[34,42]$. Infants born $<37$ or $>42$ weeks, twins, or those with medical illnesses that required prolonged hospitalization were excluded from the analysis.

2.1. Statistical Analysis. The statistical analysis was conducted using SPSS version 19.0. Categorical variables are presented as counts and percentages. Continuous variables are presented as mean \pm standard deviation. Variables with skewed distributions were logarithmically transformed. Bivariate analysis of continuous variables with infant weight gain and weight-for-length $z$-score were assessed by Spearman's correlation analysis. Independent samples $t$-test or one-way analysis of variance (ANOVA) and post hoc analysis (Fisher's least significant difference) were used to test differences in the outcome variables with maternal 
glucose tolerance group (GDM, GIGT, or NGT), GDM status (yes/no), family history of diabetes (yes/no), infant gender (male/female), ethnicity (Caucasian or non-Caucasian), age of introduction to formula (at birth, 1-5 months, $\geq 6$ months or never), and average daily screen time divided into 3 categories (no screen time, $<60$ minutes, and $\geq 60$ minutes). We converted age of introduction to formula into a categorical variable because although exclusive breastfeeding duration and age of introduction to formula are similar variables, they are not synonymous because some infants were never formula-fed $(n=80)$.

Variables determined to be significant from bivariate analyses, concurrently with variables known to influence infant weight gain and adiposity, were entered into multiple linear regression models. Two separate models were created for weight gain from birth to 1 year and weight-for-length $z$-score at 1 year. Nonmodifiable risk factors (infant age, sex, ethnicity, birth weight, and family history of diabetes) were forced into the model and modifiable risk factors (maternal prepregnancy BMI, GDM status, maternal physical activity indices prior to pregnancy, socioeconomic status, maternal $\log$ IS $_{\text {OGTT }}$, infant exclusive breastfeeding duration, age of introduction to formula, age of introduction to cereal, and daily screen time) were entered according to the forward stepwise method.

\section{Results}

Descriptive characteristics and lifestyle measures are presented in Table 1 for mothers and infants at 1-year postpartum $(n=246)$. From the time of consent postnatally to the 1-year followup visit, $62(20 \%)$ of the original 311 infants were lost to followup. There were no significant differences in GDM status, prepregnancy BMI, maternal education, or maternal physical activity between mothers retained in the study versus those lost to followup.

No significant differences were found for infant weight gain and weight-for-length $z$-score based on the mother's GDM status (yes/no) or glucose tolerance group during pregnancy (GDM, GIGT, or NGT). Independent samples $t$-tests also showed no significant differences in the infant outcomes for family history of diabetes (yes/no) and infant ethnicity (Caucasian or non-Caucasian). Males had greater weight gain than females $(P<0.001)$, however no differences between males and females for weight-for-length $z$-score were found $(P=0.636)$. One-way ANOVA showed significant differences in infant weight gain for age of formula introduction $(P=0.001)$ and screen time $(P=0.032)$ (Figure 1). Similar trends for age of formula introduction were found for infant weight-for-length $z$-score at 1 year $(P=0.012)$. However no differences were found between 0 , $<60$ min, or $\geq 60$ minutes of daily screen time $(P=0.19)$.

Spearman's correlation analysis (Table 2 ) showed a negative association for infant weight gain with maternal pregravid vigorous/sport index $(P=0.031)$, exclusive breastfeeding duration $(P<0.001)$, and an earlier age of introduction to cereal $(P=0.02)$. Weight-for-length $z$-score was positively associated with maternal prepregnancy BMI
$(P=0.003)$ and birth weight $(P<0.001)$, and negatively associated with maternal log IS $_{\text {OGTT }}$ during pregnancy $(P=0.031)$ and maternal pregravid vigorous/sport index $(P=0.006)$. Maternal pregravid vigorous/sport index was also positively correlated with IS $_{\text {OGTT }}$ during pregnancy $(P<0.001)$, as expected from previous data [43].

Results for the multivariate analyses are presented in Table 3. Each month of prolonged exclusive breastfeeding reduced weight gain by $116.4 \mathrm{~g}$, after adjustment for infant age, sex, infant ethnicity, family history of diabetes, and maternal pregravid vigorous/sport index $(P<0.001)$. After adjustment, each unit increase in maternal pregravid vigorous/sport index decreased weight gain by $218.6 \mathrm{~g}(P=$ $0.016)$. In total, $33 \%$ of the variance in the model for weight gain was explained by the sample. Infant birth weight, infant ethnicity, and family history of diabetes did not significantly predict infant weight gain at 1 year. Additionally, socioeconomic status, maternal prepregnancy BMI, maternal IS OGTT, GDM status, maternal pregravid work index, maternal pregravid leisure index, infant age of introduction to formula, and infant screen time did not emerge in the model when entered. For weight-for-length $z$-score, an increase in one unit of maternal prepregnancy BMI $\left(\mathrm{kg} / \mathrm{m}^{2}\right)$ was associated with an increase in weight-for-length $z$-score of $0.03(P=$ 0.016 ), or one standard deviation change on the WHO child growth standards, after adjustment. Thus, mothers with a greater prepregnancy BMI were more likely to have heavier infants normalized for length. In addition, each month of prolonged exclusive breastfeeding and unit increase in maternal pregravid vigorous/sport index decreased weightfor-length $z$-score by $0.08(P=0.010)$ and $0.20(P=0.031)$, respectively. Infant sex, infant ethnicity, and family history of diabetes were not significantly associated with infant weightfor-length $z$-score. Variables that did not emerge in the model included: socioeconomic status, maternal IS OGTT, GDM status, maternal pregravid work index, maternal pregravid leisure index, infant age of introduction to formula, and infant screen time. Approximately, $19 \%$ of the variance in the model for weight-for-length $z$-score was explained by the sample.

\section{Discussion}

These findings demonstrate that maternal pregravid physical activity, prepregnancy BMI, and infant feeding practices have a significant influence on infant weight gain and adiposity. Weight gain from birth to 1 year was negatively predicted by infant female sex, maternal pregravid vigorous/sport activity, and exclusive breastfeeding duration and positively predicted by infant age at time of 1 year visit. Weight-for-length $z$ score at 1 year was negatively predicted by maternal pregravid vigorous/sport activity and exclusive breastfeeding duration and positively predicted by birth weight, infant age at time of 1 year visit, and maternal prepregnancy BMI. Factors that have been previously shown to influence infant weight gain and weight-for-length $z$-score, such as socioeconomic status or GDM status, were not significant in our model. This may be due to the fact that women in this study tended to have 
TABLE 1: Maternal and infant descriptive characteristics $(n=246)$.

\begin{tabular}{|c|c|c|c|c|}
\hline & & Mean \pm SD & & $N(\%)$ \\
\hline \multirow{12}{*}{ Maternal factors } & Age (years) & $34.2 \pm 4.7$ & OGTT status & \\
\hline & Prepregnancy BMI $\left(\mathrm{kg} / \mathrm{m}^{2}\right)$ & $29.0 \pm 5.2$ & GDM & $70(28.5)$ \\
\hline & SES (Hollingshead index) & $51.8 \pm 8.3$ & GIGT & $38(15.4)$ \\
\hline & Maternal Insulin sensitivity & $5.5 \pm 3.6$ & NGT & $138(56.1)$ \\
\hline & Pregravid physical activity & & Family history of diabetes & $146(59.3)$ \\
\hline & Work index & $2.4 \pm 0.6$ & & \\
\hline & Vigorous/sport index & $2.4 \pm 0.8$ & & \\
\hline & Leisure index & $3.1 \pm 0.6$ & & \\
\hline & Physical Activity 1-year postpartum & & & \\
\hline & Work index & $3.0 \pm 0.6$ & & \\
\hline & Vigorous/Sport Index & $2.3 \pm 0.8$ & & \\
\hline & Leisure Index & $3.1 \pm 0.6$ & & \\
\hline \multirow{12}{*}{ Infant factors } & Birth weight $(\mathrm{g})$ & $3438.2 \pm 456.8$ & Age of introduction to formula* & \\
\hline & Gestation (weeks) & $39 \pm 1.4$ & At birth & $45(18.3)$ \\
\hline & Age at time of visit (months) & $12.4 \pm 1.2$ & $1-5$ months & $55(22.4)$ \\
\hline & & & After 6 months & $62(25.2)$ \\
\hline & Exclusive breastfeeding duration (months) & $4.5 \pm 2.3$ & Never & $80(32.5)$ \\
\hline & Age of introduction to cereal (months) & $5.5 \pm 1.1$ & Females & $126(51.2)$ \\
\hline & Daily screen time (min) & $48.9 \pm 99.8$ & Caucasian & $156(63.4)$ \\
\hline & & & Screen time & \\
\hline & $\Delta$ Weight from $0-1$ year $(\mathrm{g})$ & $6312.7 \pm 1116.1$ & None & $93(38)$ \\
\hline & Weight-for-length $z$-score & $0.23 \pm 1.0$ & $<60 \min$ & $76(31)$ \\
\hline & & & $60-119 \min$ & $48(20)$ \\
\hline & & & $\geq 120 \mathrm{~min}$ & $28(11)$ \\
\hline
\end{tabular}

${ }^{*} 4$ infants were missing information for age of introduction to formula.

SES: socioeconomic status; GDM: gestational diabetes mellitus; GIGT: gestational impaired glucose tolerance; NGT: normal glucose tolerance; $\Delta$ Weight: change in weight from 0 to 1 year.

TABLE 2: Spearman's rho correlation for $\Delta$ weight from 0 -1 year and weight-for-length $z$-score at 1 year.

\begin{tabular}{|c|c|c|c|c|}
\hline & \multicolumn{2}{|c|}{$\Delta$ Weight $(0-1$ year $)$} & \multicolumn{2}{|c|}{ Weight-for-length $z$-score at 1 year } \\
\hline & $r$ & $P$ & $r$ & $P$ \\
\hline Maternal age & -0.078 & 0.224 & -0.079 & 0.223 \\
\hline Socioeconomic status & 0.027 & 0.695 & -0.030 & 0.664 \\
\hline Maternal $\log$ IS $_{\text {OGTT }}$ & -0.070 & 0.277 & -0.139 & 0.031 \\
\hline Maternal prepregnancy BMI & 0.097 & 0.132 & 0.189 & 0.003 \\
\hline Maternal pregravid work index & -0.009 & 0.896 & 0.027 & 0.683 \\
\hline Maternal pregravid vigorous/sport index & -0.139 & 0.031 & -0.177 & 0.006 \\
\hline Maternal pregravid leisure index & -0.036 & 0.582 & -0.017 & 0.795 \\
\hline Infant age at time of visit & 0.309 & $<0.001$ & 0.116 & 0.071 \\
\hline Infant birth weight & 0.062 & 0.330 & 0.302 & $<0.001$ \\
\hline Exclusive breastfeeding duration & -0.234 & $<0.001$ & -0.166 & 0.012 \\
\hline Age of introduction to cereal & -0.150 & 0.020 & -0.060 & 0.356 \\
\hline Infant screen time & 0.100 & 0.118 & 0.081 & 0.207 \\
\hline
\end{tabular}

excellent glycemic control, which was evidenced by normal birth weight in the GDM pregnancies. In addition, families tended to be from mid to high socioeconomic status.

The effect of maternal prepregnancy BMI on infant adiposity is consistent with existing literature [12-14, 31]. In mothers with NGT or GDM, maternal prepregnancy BMI was significantly associated with childhood overweight in both groups, even after adjustment for maternal glucose status and infant birth weight [12]. Furthermore, Knight and colleagues reported that the impact of maternal fasting plasma glucose in nondiabetic mothers on infant growth was transient, while maternal prepregnancy BMI and paternal BMI remained correlated with offspring BMI at 2 years of age. Thus, the authors suggested that parental obesity, shared 

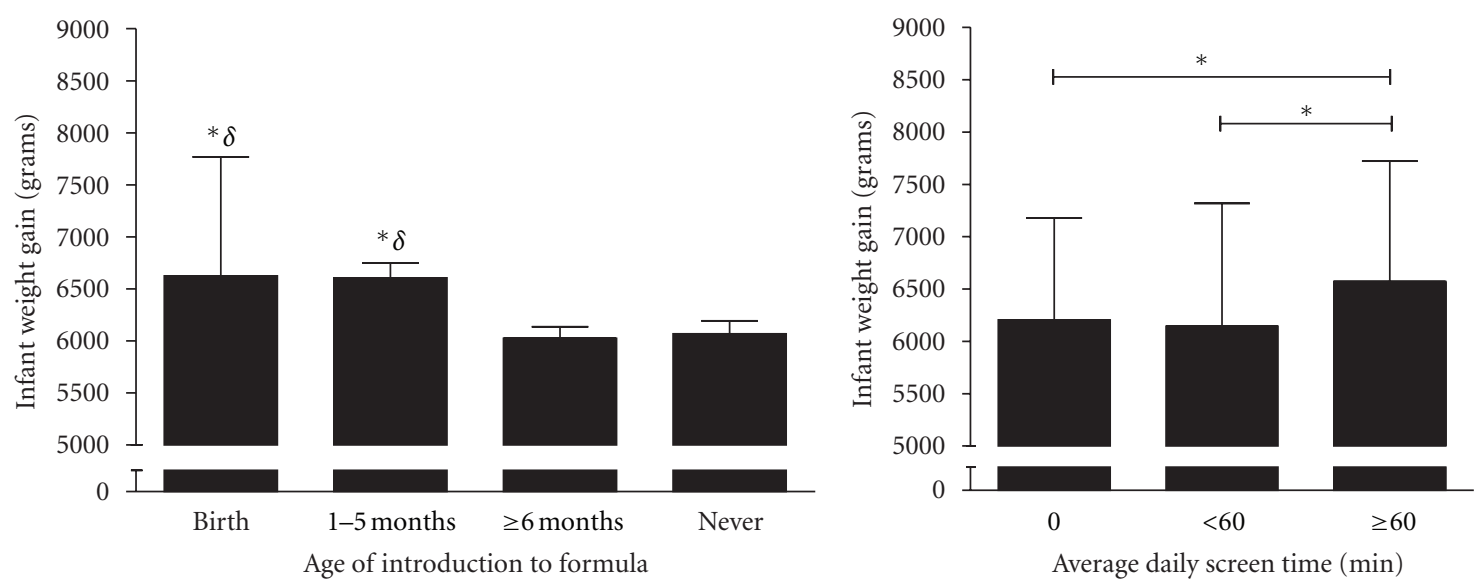

(a) * Significantly different from age of introduction of formula at 6 months or later, $\delta$ Significantly different from infants never introduced to formula

(b) * Significantly different from infants with greater than 60 min of screen time

FIgURE 1: Age of introduction to formula (a) and screen time (b) on infant weight gain at 1 year.

TABLE 3: Multiple linear regression analysis of dependent variables $\Delta$ weight (0-1 year) and weight-for-length $z$-score, respectively.

\begin{tabular}{|c|c|c|c|}
\hline & $B$ & $t$ & $P$ \\
\hline \multicolumn{4}{|l|}{$\Delta$ Weight $(0-1$ year $)$} \\
\hline Birth weight & -0.01 & -0.06 & 0.950 \\
\hline Infant age at 1 year visit & 339.56 & 5.82 & $<0.001$ \\
\hline Infant sex (female) & -648.43 & -4.76 & $<0.001$ \\
\hline Infant ethnicity & 260.53 & 1.84 & 0.067 \\
\hline Family history of diabetes & -62.29 & -0.45 & 0.651 \\
\hline Maternal pregravid vigorous/sport index & -218.64 & -2.44 & 0.016 \\
\hline \multirow[t]{2}{*}{ Exclusive breastfeeding duration } & -116.37 & -3.97 & $<0.001$ \\
\hline & & & $R^{2}=33 \%$ \\
\hline \multicolumn{4}{|l|}{ Weight-for-length $z$-score at 1 year } \\
\hline Birth weight & 0.00 & 3.50 & 0.001 \\
\hline Infant age at 1 year visit & 0.12 & 2.00 & 0.047 \\
\hline Infant sex (female) & 0.02 & 0.13 & 0.894 \\
\hline Infant ethnicity & 0.20 & 1.41 & 0.160 \\
\hline Family history of diabetes & -0.11 & -0.78 & 0.439 \\
\hline Maternal prepregnancy BMI & 0.03 & 2.43 & 0.016 \\
\hline Maternal pregravid vigorous/sport index & -0.20 & -2.17 & 0.031 \\
\hline \multirow[t]{2}{*}{ Exclusive breastfeeding duration } & -0.08 & -2.59 & 0.010 \\
\hline & & & $R^{2}=19 \%$ \\
\hline
\end{tabular}

Parameters. (i) Forced: Birth weight, infant age at 1 year visit, infant sex, infant ethnicity (Caucasian versus non-Caucasian), family history of diabetes; (ii) forward stepwise method: socioeconomic status, maternal prepregnancy BMI, Maternal log IS OGTT, maternal GDM status during pregnancy (yes/no), maternal pregravid work index, maternal pregravid vigorous/sport index, maternal pre-gravid leisure index, exclusive breastfeeding duration, age of introduction to formula (at birth, before 6 months, after 6 months, never), age of introduction to cereal, and daily screen time.

GDM: gestational diabetes mellitus; IS $\mathrm{OGGTT}_{\text {: }}$ oral glucose tolerance testing for assessment of insulin sensitivity.

environment, or genetic factors had a greater influence on childhood BMI than maternal fasting plasma glucose during pregnancy [44].

We also found that the maternal environment has an important role on infant growth. After controlling for confounding factors, maternal pregravid vigorous/sport activity significantly predicted infant weight gain. The mean pregravid vigorous/sport index in our study was 2.4 , which suggests that $15-30 \mathrm{~min}$ of walking or cycling per day [37] in mothers prior to pregnancy may be beneficial for decreasing obesity risk of offspring. Maternal log IS OGTT did not predict infant growth at 1 year, after adjusting for maternal physical activity indices. Prior analyses by our group showed pregravid vigorous/sport activity was an independent predictor of maternal IS OGTT and reduced glucose intolerance in pregnancy [43]. Taken together, pregravid 
physical activity may affect infant weight gain through a mechanism that partly involves maternal IS OGTT $_{\text {, however, }}$ these results suggest that maternal lifestyle may have a greater impact on infant weight gain than maternal glucose tolerance group or IS OGTT.

Although daily screen time was not a significant predictor of infant weight gain or adiposity in our multivariate analyses, it was unsettling to find that more than half of the infants in our study were already exposed to television at 1 year of age and $11 \%$ of infants watched more than 2 hours of television per day. Infants with $\geq 60$ minutes of screen time each day were heavier at 1 year of age than infants with 0 or $<60$ minutes of daily screen time. One possible explanation may include decreased overall activity levels in infants exposed to television for longer periods of time. However, further examination of infant activity is necessary. In US preschool children, more than 2 hours of television per day was associated with a higher risk of overweight and at risk for overweight and greater adiposity [45]. Despite the known effect of screen time on BMI in childhood [45-47], there is currently limited information on the effect of screen time under 2 years of age.

The mechanisms to explain the effects of breastfeeding compared to formula feeding may include different physiological and behavioural factors. Several studies [24-27], however not all $[32,48,49]$, suggest that breastfeeding has a protective role on later obesity risk. After adjusting for confounding variables, infants exclusively breast fed for a longer duration had reduced weight gain and adiposity at 1 year. This may be influenced by the unique metabolic factors in breast milk compared to formula, such as breast milk leptin [50,51] and adiponectin [52] that may induce earlier satiety. The higher protein content of formula may also contribute to increased adiposity in formula fed infants. Koletzko and colleagues demonstrated that infants given formula with high protein content compared to infants given formula with low protein content resulted in increased weight at 2 years of age with no effect on infant length [53]. It is thought that the higher protein consumption results in higher insulin secretion and stimulates the expression of insulin-like growth factor I (IGF-I), leading to more adipogenic activity and adipocyte differentiation [54, 55]. Additionally, behavioural differences between breast-fed and formula-fed infants may affect infant energy intake. Studies have shown that there is less maternal control and a greater response to the infant's hunger and satiety cues with breastfeeding compared to formula feeding $[56,57]$. There is also a lower frequency of meals and a higher uniformity of feeding volumes in formula-fed infants compared to breastfed infants [58].

Although some studies have reported the timing of cereal introduction as a positive predictor of infant weight gain [14], it did not emerge in our multivariate analyses. In a recent study, Huh and colleagues noted that the timing of the introduction of solid foods on the odds of obesity at 3 years of age varied by breastfeeding status. Infants that were introduced to solid foods before 4 months and were never breast fed or stopped breastfeeding before 4 months had a sixfold increase in the odds of obesity compared to infants breast fed for more than 4 months [59]. Since our study population was introduced to cereal later than 4 months $(5.5 \pm 1.1$ months), this may explain why cereal introduction did not affect weight gain or adiposity. Altogether, our findings on infant feeding suggest that exclusive breastfeeding duration may be more predictive of infant weight gain and adiposity than age of formula or cereal introduction.

This study should be viewed in context of certain strengths and limitations. Due to the assessment of glucose tolerance in the late 2nd or 3rd trimester of pregnancy, we cannot completely exclude the possibility that some individuals may have received treatments following OGTT that could affect in utero glucose exposure and IS OGTT $_{\text {Th }}$ on infant outcomes. Although data was available on the type of intervention (diet therapy or other), glycemic control during pregnancy could not be determined. Other limitations included the lack of data on maternal diet and maternal physical activity during pregnancy in our study. Gluck et al. proposed that maternal energy intake influenced energy intake in children more than intrauterine exposure to diabetes [60], which suggests maternal energy intake should be included in future studies. Additionally, our study population had a large proportion of Caucasian infants and highly educated parents, and it is unclear whether results may be extended to other ethnic backgrounds or families with lower socioeconomic status. Loss to followup was $20 \%$, and although there were no differences in maternal factors between those who left and remained in the study, feeding practices of the infants may have differed. We were also unable to report on infant physical activity due to challenges in capturing physical activity accurately and objectively in infants. Nevertheless, we examined maternal and infant lifestyle variables that have not been previously studied together, providing further insight into the effects of the maternal and infant environment on weight gain and adiposity while controlling for important confounding variables.

In summary, increased maternal pregravid physical activity and longer exclusive breastfeeding duration may have a critical influence on reducing infant weight gain and adiposity as early as 1 year of age. Results from this study support the recommendation for exclusive breastfeeding in infancy, and suggest maternal physical activity may also influence postnatal outcomes. Future directions include examining the additive effects of maternal diet during and after pregnancy, infant physical activity, and sedentary time on infant weight gain and adiposity. The evaluation of paternal physical activity may also provide insight into the impact of family lifestyle on infant growth. Longitudinal followup of these children will examine the effects of maternal and infant factors on BMI and adiposity in early childhood beyond 1 year of age.

\section{Abbreviations}

BMI: Body mass index

GDM: Gestational diabetes mellitus

OGTT: Oral glucose tolerance test 
NDDG: National Diabetes Data Group

GIGT: Gestational impaired glucose tolerance

NGT: Normal glucose tolerance

IS OGTT: Maternal insulin sensitivity.

\section{Conflict of Interests}

The authors have no conflict of interests to declare.

\section{Acknowledgments}

The authors are grateful for the families who participated in the study. They wish to thank their research coordinators Amy Newcombe, Paula Van Nostrand, and Maria Luzardo, the Hospital for Sick Children Clinical Investigative Unit and Mount Sinai Hospital Department of Pathology and Laboratory Medicine and Patient Care Services.This study was supported by operating Grants from the Canadian Institutes of Health Research (CIHR) (OCO-742471, MOP-89831, and MOP-84206) and the Canadian Diabetes Association (CDA) (OG-3-08-2543-RR). R. Retnakaran holds a CIHR Clinical Research Initiative New Investigator Award and CDA Clinician-Scientist incentive funding. A. J. G. Hanley holds a Tier-II Canada Research Chair in Diabetes Epidemiology. B. Zinman holds the Sam and Judy Pencer Family Chair in Diabetes Research at Mount Sinai Hospital and University of Toronto.

\section{References}

[1] Y. Wang and T. Lobstein, "Worldwide trends in childhood overweight and obesity," International Journal of Pediatric Obesity, vol. 1, no. 1, pp. 11-25, 2006.

[2] M. De Onis, M. Blössner, and E. Borghi, "Global prevalence and trends of overweight and obesity among preschool children," American Journal of Clinical Nutrition, vol. 92, no. 5, pp. 1257-1264, 2010.

[3] L. Aerts and F. A. Van Assche, "Intra-uterine transmission of disease," Placenta, vol. 24, no. 10, pp. 905-911, 2003.

[4] N. Freinkel, "Of pregnancy and progeny," Diabetes, vol. 29, no. 12, pp. 1023-1035, 1980.

[5] K. Ong and R. Loos, "Rapid infancy weight gain and subsequent obesity: systematic reviews and hopeful suggestions," Acta Paediatrica, International Journal of Paediatrics, vol. 95, no. 8, pp. 904-908, 2006.

[6] U. Ekelund, K. K. Ong, Y. Linné et al., "Association of weight gain in infancy and early childhood with metabolic risk in young adults," Journal of Clinical Endocrinology and Metabolism, vol. 92, no. 1, pp. 98-103, 2007.

[7] N. Stettler, "Nature and strength of epidemiological evidence for origins of childhood and adulthood obesity in the first year of life," International Journal of Obesity, vol. 31, no. 7, pp. 1035-1043, 2007.

[8] E. W. Demerath, D. Reed, A. C. Choh et al., "Rapid postnatal weight gain and visceral adiposity in adulthood: the fels longitudinal study," Obesity, vol. 17, no. 11, pp. 2060-2066, 2009.

[9] P. M. Catalano, A. Thomas, L. Huston-Presley, and S. B. Amini, "Increased fetal adiposity: a very sensitive marker of abnormal in utero development," American Journal of
Obstetrics and Gynecology, vol. 189, no. 6, pp. 1698-1704, 2003.

[10] D. Dabelea, W. C. Knowler, and D. J. Pettitt, "Effect of diabetes in pregnancy on offspring: follow-up research in the Pima Indians," Journal of Maternal-Fetal and Neonatal Medicine, vol. 9, no. 1, pp. 83-88, 2000.

[11] P. W. Franks, H. C. Looker, S. Kobes et al., "Gestational glucose tolerance and risk of type 2 diabetes in young Pima Indian offspring," Diabetes, vol. 55, no. 2, pp. 460-465, 2006.

[12] P. M. Catalano, K. Farrell, A. Thomas et al., "Perinatal risk factors for childhood obesity and metabolic dysregulation," American Journal of Clinical Nutrition, vol. 90, no. 5, pp. 13031313, 2009.

[13] R. C. Whitaker, "Predicting preschooler obesity at birth: the role of maternal obesity in early pregnancy," Pediatrics, vol. 114, no. 1, pp. e29-e36, 2004.

[14] J. L. Baker, K. F. Michaelsen, K. M. Rasmussen, and T. I. A. Sørensen, "Maternal prepregnant body mass index, duration of breastfeeding, and timing of complementary food introduction are associated with infant weight gain," American Journal of Clinical Nutrition, vol. 80, no. 6, pp. 1579-1588, 2004.

[15] J. K. Hamilton, E. Odrobina, J. Yin, A. J. Hanley, B. Zinman, and R. Retnakaran, "Maternal insulin sensitivity during pregnancy predicts infant weight gain and adiposity at 1 year of age," Obesity, vol. 18, no. 2, pp. 340-346, 2010.

[16] R. G. Moses, M. Luebcke, W. S. Davis et al., "Effect of a lowglycemic-index diet during pregnancy on obstetric outcomes," American Journal of Clinical Nutrition, vol. 84, no. 4, pp. 807812, 2006.

[17] J. F. Clapp, "Maternal carbohydrate intake and pregnancy outcome," Proceedings of the Nutrition Society, vol. 61, no. 1, pp. 45-50, 2002.

[18] J. F. Clapp, "Influence of endurance exercise and diet on human placental development and fetal growth," Placenta, vol. 27, no. 6-7, pp. 527-534, 2006.

[19] S. A. Hopkins, J. C. Baldi, W. S. Cutfield, L. McCowan, and P. L. Hofman, "Exercise training in pregnancy reduces offspring size without changes in maternal insulin sensitivity," Journal of Clinical Endocrinology and Metabolism, vol. 95, no. 5, pp. 2080-2088, 2010.

[20] C. Syme, M. Abrahamowicz, A. Mahboubi et al., "Prenatal exposure to maternal cigarette smoking and accumulation of intra-abdominal fat during adolescence," Obesity, vol. 18, no. 5, pp. 1021-1025, 2010.

[21] T. Mizutani, K. Suzuki, N. Kondo, and Z. Yamagata, "Association of maternal lifestyles including smoking during pregnancy with childhood obesity," Obesity, vol. 15, no. 12, pp. 3133-3139, 2007.

[22] E. Oken, E. B. Levitan, and M. W. Gillman, "Maternal smoking during pregnancy and child overweight: systematic review and meta-analysis," International Journal of Obesity, vol. 32, no. 2, pp. 201-210, 2008.

[23] A. Toschke, B. Koletzko, W. Slikker, M. Hermann, and R. Von Kries, "Childhood obesity is associated with maternal smoking in pregnancy," European Journal of Pediatrics, vol. 161, no. 8, pp. 445-448, 2002.

[24] A. Plagemann and T. Harder, "Breast feeding and the risk of obesity and related metabolic diseases in the child," Metabolic Syndrome and Related Disorders, vol. 3, no. 3, pp. 222-232, 2005.

[25] T. Harder, E. Rodekamp, K. Schellong, J. W. Dudenhausen, and A. Plagemann, "Birth weight and subsequent risk of type 
2 diabetes: a meta-analysis," American Journal of Epidemiology, vol. 165, no. 8, pp. 849-857, 2007.

[26] P. Hoddinott, D. Tappin, and C. Wright, "Breast feeding," British Medical Journal, vol. 336, no. 7649, pp. 881-887, 2008.

[27] L. M. Grummer-Strawn and Z. Mei, "Does breastfeeding protect against pediatric overweight? Analysis of longitudinal data from the Centers for Disease Control and Prevention Pediatric Nutrition Surveillance System," Pediatrics, vol. 113, no. 2, pp. e81-e86, 2004.

[28] T. Harder, R. Bergmann, G. Kallischnigg, and A. Plagemann, "Duration of breastfeeding and risk of overweight: a metaanalysis," American Journal of Epidemiology, vol. 162, no. 5, pp. 397-403, 2005.

[29] M. S. Kramer, T. Guo, R. W. Platt et al., "Feeding effects on growth during infancy," Journal of Pediatrics, vol. 145, no. 5, pp. 600-605, 2004.

[30] I. Gunnarsdottir, L. Schack-Nielsen, K. F. Michaelsen, T. I. A. Sørensen, and I. Thorsdottir, "Infant weight gain, duration of exclusive breast-feeding and childhood BMI-two similar follow-up cohorts," Public Health Nutrition, vol. 13, no. 2, pp. 201-207, 2010.

[31] C. Li, H. Kaur, W. S. Choi, T. T. K. Huang, R. E. Lee, and J. S. Ahluwalia, "Additive interactions of maternal prepregnancy BMI and breast-feeding on childhood overweight," Obesity Research, vol. 13, no. 2, pp. 362-371, 2005.

[32] H. L. Burdette, R. C. Whitaker, W. C. Hall, and S. R. Daniels, "Breastfeeding, introduction of complementary foods, and adiposity at 5 y of age," American Journal of Clinical Nutrition, vol. 83, no. 3, pp. 550-558, 2006.

[33] L. K. Certain and R. S. Kahn, "Prevalence, correlates, and trajectory of television viewing among infants and toddlers," Pediatrics, vol. 109, no. 4, pp. 634-642, 2002.

[34] S. E. Barlow, "Expert committee recommendations regarding the prevention, assessment, and treatment of child and adolescent overweight and obesity: summary report," Pediatrics, vol. 120, supplement 4, pp. S164-192, 2007.

[35] R. Retnakaran, A. J. G. Hanley, N. Raif, P. W. Connelly, M. Sermer, and B. Zinman, "C-reactive protein and gestational diabetes: the central role of maternal obesity," Journal of Clinical Endocrinology and Metabolism, vol. 88, no. 8, pp. 3507-3512, 2003.

[36] M. Matsuda and R. A. DeFronzo, "Insulin sensitivity indices obtained from oral glucose tolerance testing: comparison with the euglycemic insulin clamp," Diabetes Care, vol. 22, no. 9, pp. 1462-1470, 1999.

[37] J. A. H. Baecke, J. Burema, and J. E. R. Frijters, "A short questionnaire for the measurement of habitual physical activity in epidemiological studies," American Journal of Clinical Nutrition, vol. 36, no. 5, pp. 936-942, 1982.

[38] M. A. Pereira, S. J. FitzerGerald, E. W. Gregg et al., "A collection of physical Activity Questionnaires for healthrelated research," Medicine and science in sports and exercise, vol. 29, supplement 6, pp. S1-S205, 1997.

[39] B. E. Ainsworth, W. L. Haskell, M. C. Whitt et al., "Compendium of physical activities: an update of activity codes and MET intensities," Medicine and Science in Sports and Exercise, vol. 32, supplement 9, pp. S498-S504, 2000.

[40] A. Hollingshead, Hollingshead Four Factor Index of Social Status, Department of Sociology, Yale University, New Haven, Conn, USA, 1975.

[41] C. Wright, R. Lakshman, P. Emmett, and K. K. Ong, "Implications of adopting the WHO 2006 Child Growth Standard in the UK: two prospective cohort studies," Archives of Disease in Childhood, vol. 93, no. 7, pp. 566-569, 2008.
[42] B. A. Dennison, T. A. Erb, and P. L. Jenkins, "Television viewing and television in bedroom associated with overweight risk among low-income preschool children," Pediatrics, vol. 109, no. 6, pp. 1028-1035, 2002.

[43] R. Retnakaran, Y. Qi, M. Sermer, P. W. Connelly, B. Zinman, and A. J. G. Hanley, "Pre-gravid physical activity and reduced risk of glucose intolerance in pregnancy: the role of insulin sensitivity," Clinical Endocrinology, vol. 70, no. 4, pp. 615-622, 2009.

[44] B. Knight, B. M. Shields, A. Hill, R. J. Powell, D. Wright, and A. T. Hattersley, "The impact of maternal glycemia and obesity on early postnatal growth in a nondiabetic caucasian population," Diabetes Care, vol. 30, no. 4, pp. 777-783, 2007.

[45] J. A. Mendoza, F. J. Zimmerman, and D. A. Christakis, "Television viewing, computer use, obesity, and adiposity in US preschool children," International Journal of Behavioral Nutrition and Physical Activity, vol. 4, article 44, 2007.

[46] R. Jago, T. Baranowski, J. C. Baranowski, D. Thompson, and K. A. Greaves, "BMI from 3-6y of age is predicted by TV viewing and physical activity, not diet," International Journal of Obesity, vol. 29, no. 6, pp. 557-564, 2005.

[47] A. Beyerlein, A. M. Toschke, and R. Von Kries, "Risk factors for childhood overweight: shift of the mean body mass index and shift of the upper percentiles: results from a cross-sectional study," International Journal of Obesity, vol. 34, no. 4, pp. 642648, 2010.

[48] M. S. Kramer, L. Matush, I. Vanilovich et al., "A randomized breast-feeding promotion intervention did not reduce child obesity in belarus," Journal of Nutrition, vol. 139, no. 2, pp. 417S-421S, 2009.

[49] K. Huus, J. F. Ludvigsson, K. Enskär, and J. Ludvigsson, "Exclusive breastfeeding of Swedish children and its possible influence on the development of obesity: a prospective cohort study," BMC Pediatrics, vol. 8, article 42, 2008.

[50] O. Miralles, J. Sánchez, A. Palou, and C. Picó, "A physiological role of breast milk leptin in body weight control in developing infants," Obesity, vol. 14, no. 8, pp. 1371-1377, 2006.

[51] F. Savino, M. F. Fissore, E. C. Grassino, G. E. Nanni, R. Oggero, and L. Silvestro, "Ghrelin, leptin and IGF-I levels in breastfed and formula-fed infants in the first years of life," Acta Paediatrica, International Journal of Paediatrics, vol. 94, no. 5, pp. 531-537, 2005.

[52] J. G. Woo, M. L. Guerrero, M. Altaye et al., "Human milk adiponectin is associated with infant growth in two independent cohorts," Breastfeeding Medicine, vol. 4, no. 2, pp. 101-109, 2009.

[53] B. Koletzko, R. Von Kries, R. Closa et al., "Lower protein in infant formula is associated with lower weight up to age 2 y: a randomized clinical trial," American Journal of Clinical Nutrition, vol. 89, no. 6, pp. 1836-1845, 2009.

[54] B. Koletzko, R. Von Kries, R. Closa, and J. Escribano, "Can infant feeding choices modulate later obesity risk?" The American Journal of Clinical Nutrition, vol. 89, no. 5, pp. 1502S-1508S, 2009.

[55] H. Hauner, M. Wabitsch, K. Zwiauer, K. Widhalm, and E. F. Pfeiffer, "Adipogenic activity in sera from obese children before and after weight reduction," American Journal of Clinical Nutrition, vol. 50, no. 1, pp. 63-67, 1989.

[56] E. M. Taveras, K. S. Scanlon, L. Birch, S. L. Rifas-Shiman, J. W. Rich-Edwards, and M. W. Gillman, "Association of breastfeeding with maternal control of infant feeding at age 1 year," Pediatrics, vol. 114, no. 5, pp. e577-e583, 2004.

[57] E. M. Taveras, S. L. Rifas-Shiman, K. S. Scanlon, L. M. Grummer-Strawn, B. Sherry, and M. W. Gillman, "To what 
extent is the protective effect of breastfeeding on future overweight explained by decreased maternal feeding restriction?" Pediatrics, vol. 118, no. 6, pp. 2341-2348, 2006.

[58] E. Sievers, H. D. Oldigs, R. Santer, and J. Schaub, "Feeding patterns in breast-fed and formula-fed infants," Annals of Nutrition and Metabolism, vol. 46, no. 6, pp. 243-248, 2002.

[59] S. Y. Huh, S. L. Rifas-Shiman, E. M. Taveras, E. Oken, and M. W. Gillman, "Timing of solid food introduction and risk of obesity in preschool-aged children," Pediatrics, vol. 127, no. 3, pp. e544-e551, 2011.

[60] M. E. Gluck, C. A. Venti, R. S. Lindsay, W. C. Knowler, A. D. Salbe, and J. Krakoff, "Maternal influence, not diabetic intrauterine environment, predicts children's energy intake," Obesity, vol. 17, no. 4, pp. 772-777, 2009. 


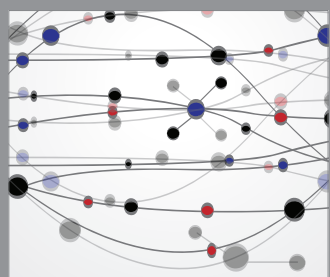

The Scientific World Journal
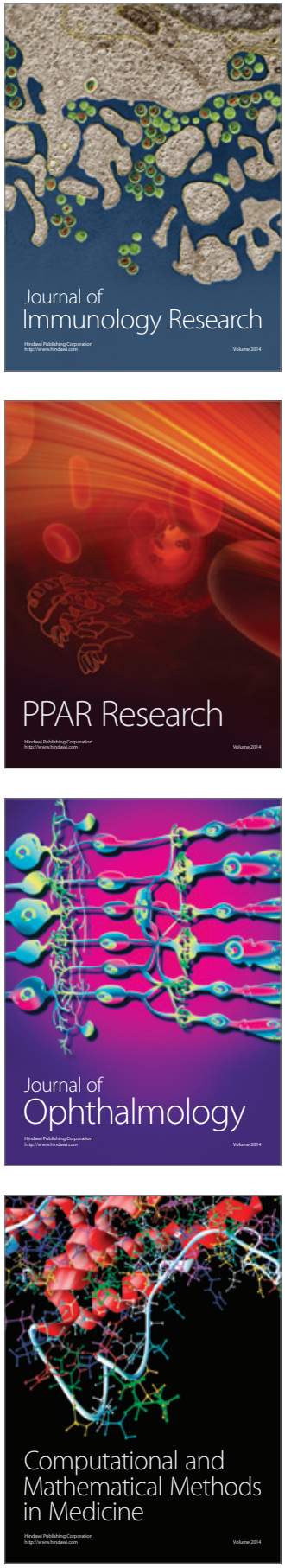

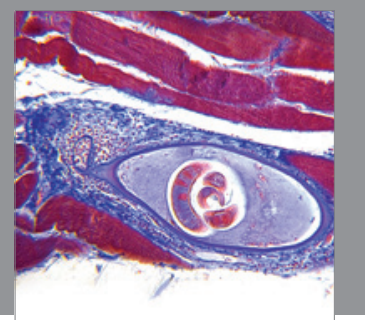

Gastroenterology

Research and Practice
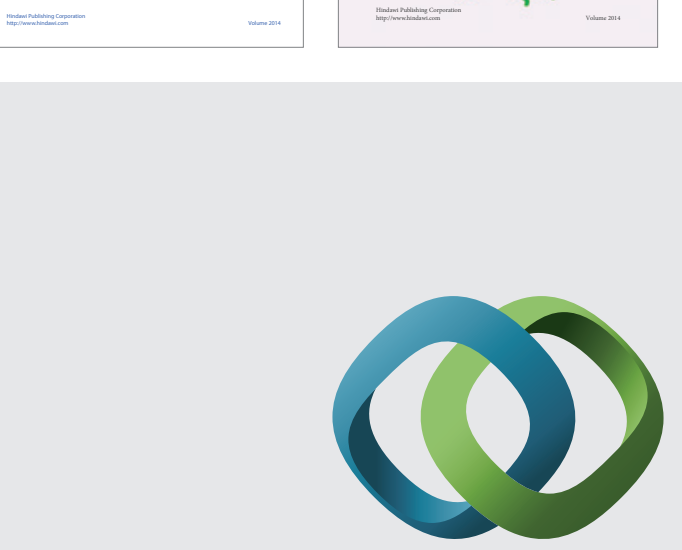

\section{Hindawi}

Submit your manuscripts at

http://www.hindawi.com
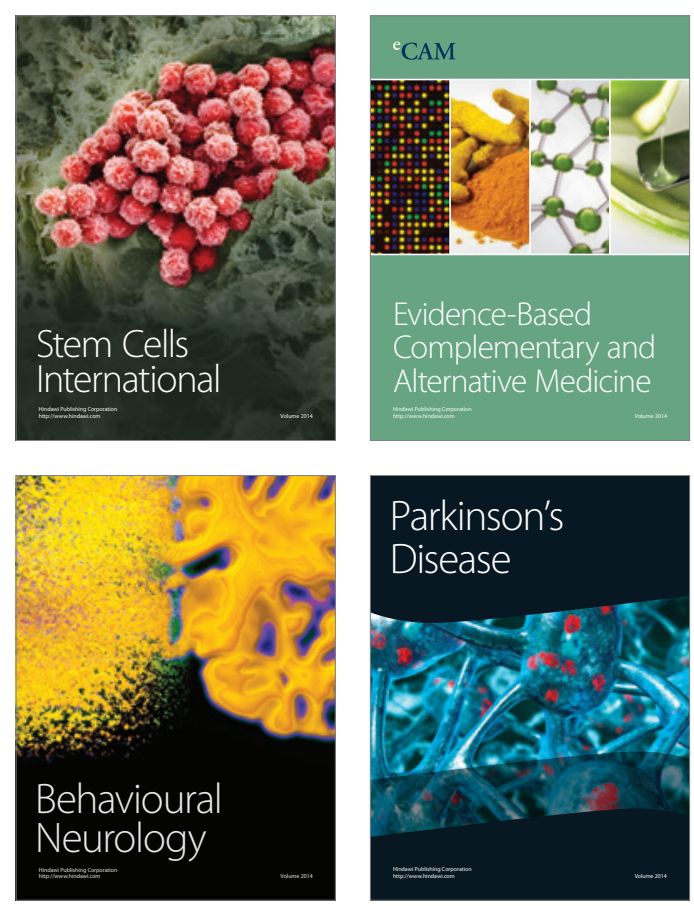

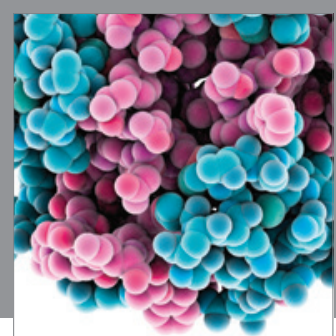

Journal of
Diabetes Research

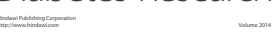

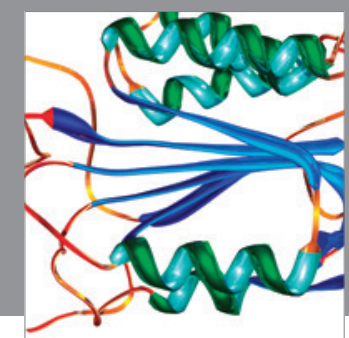

Disease Markers
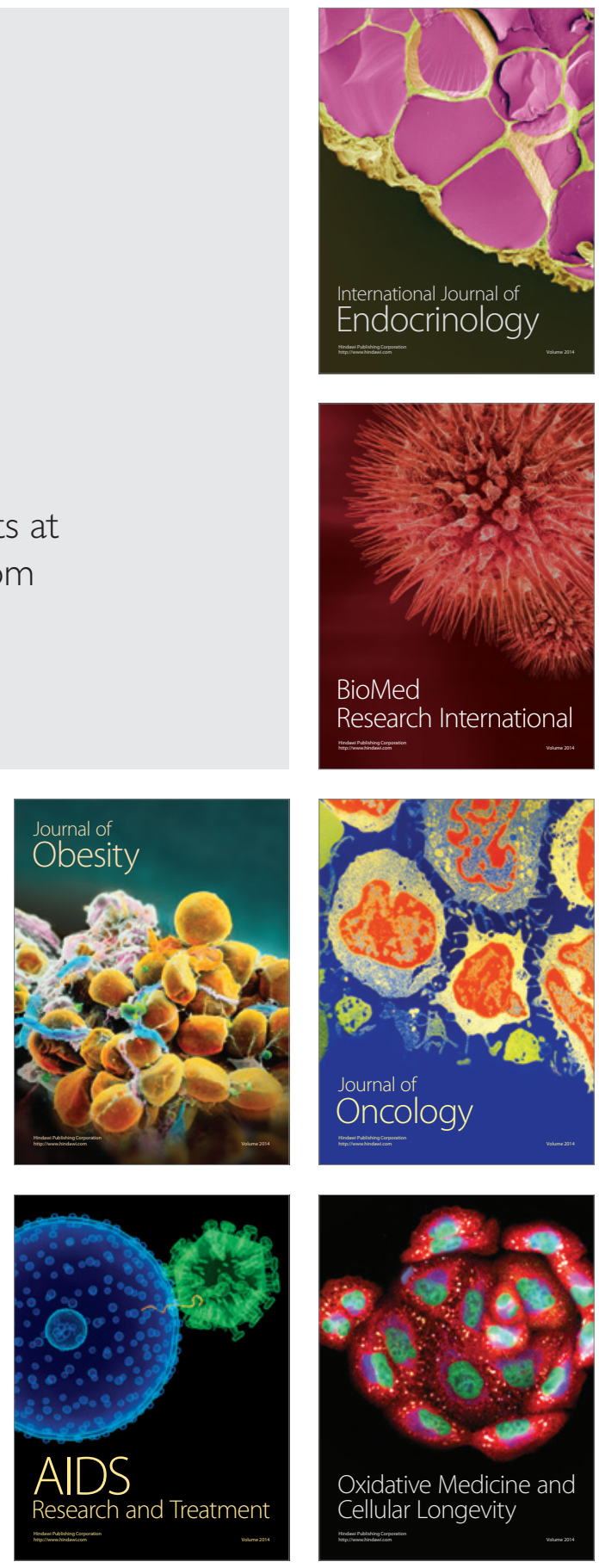